\title{
A RESPONSABILIDADE ENUNCIATIVA NO TEXTO DE DIVULGAÇÃO CIENTÍFICA MIDIÁTICA
}

\author{
Marcos Filipe Zandonai ${ }^{*}$ \\ Universidade Estadual de Ponta Grossa \\ Departamento de Estudos da Linguagem \\ Ponta Grossa, PR, Brasil
}

\author{
Maria Eduarda Giering* \\ Maria Helena Albé ${ }^{\star * *}$ \\ Universidade do Vale do Rio dos Sinos \\ Escola da Indústria Criativa \\ São Leopoldo, RS, Brasil
}

\begin{abstract}
Resumo: Este artigo objetiva mostrar marcas de (não) assunção de responsabilidade enunciativa presentes em uma reportagem de divulgação científica midiática publicada na revista Superinteressante. Para isto, baseia-se na Análise Textual dos Discursos (ATD), especificamente na noção de responsabilidade enunciativa (RE) (ADAM, 2011), nas teorizações de Guentchéva $(1994,1996)$ sobre o mediativo, e nas considerações de Charaudeau (2016) sobre midiatização da ciência. Procura entender que representações do discurso alheio são construídas, as quais fazem com que o Locutor/Enunciador (L1/E1) cumpra certas finalidades, próprias do contexto de comunicação em que está inserido. Analisa três excertos da reportagem, mediante os quais descreve como são apresentadas $e$ representadas as vozes do texto. Embora a reportagem não tenha finalidade propriamente argumentativa e Pontos de Vista (PdV) contrastantes sejam expostos, a análise evidencia que L1/E1 expressa diferentes graus de engajamento em relação a um ou outro PdV, o que indica seu posicionamento sobre os conteúdos atribuídos a terceiros.
\end{abstract}

Palavras-chave: Divulgação científica. Responsabilidade enunciativa. Orientação argumentativa.

A comunicação da ciência se realiza em situações de socialização do saber entre especialistas (em congressos, conferências, reuniões), mas também pode acontecer fora dos ambientes acadêmicos, como em documentários transmitidos em diferentes suportes

\footnotetext{
* Mestre em Linguística Aplicada pela Universidade do Vale do Rio dos Sinos. E-mail: marcosfzan@gmail.com.

** Doutora em Linguística pela Pontifícia Universidade Católica do Rio Grande do Sul (PUCRS). Professora e pesquisadora no Programa de Pós-Graduação em Linguística Aplicada (UNISINOS). E-mail: eduardajg@gmail.com.

*** Doutora pelo Programa de Pós-Graduação em Linguística Aplicada da UNISINOS. Professora no curso de Letras da mesma instituição. E-mail: mhalbe@unisinos.br.
} 
(na televisão, na Internet etc.), podcasts de ciência, museus, planetários, revistas, entre outros espaços mais ou menos institucionalizados.

Nosso interesse, aqui, é justamente compreender as estratégias de construção da comunicação científica, especificamente daquela dirigida ao auditório leigo, principiante, ou seja, a um público não totalmente familiarizado com a linguagem e o modo de pensar dos cientistas, mas que está interessado em temas da ciência e tecnologia (C\&T). Concentramo-nos na divulgação científica midiática, a qual é destinada a um público que, pelos cálculos do produtor textual, é leigo em ciência, conforme constatações já realizadas pelo grupo CCELD ${ }^{1}$ (GIERING, 2012; ZANDONAI; GIERING, 2013) a respeito dessa atividade de comunicação.

A revista Superinteressante é um dos veículos de comunicação comprometidos com a divulgação científica, pois ela aborda temas de C\&T, e, por isso, é selecionada como corpus do presente estudo. No intento de avançarmos na exploração dos modos pelos quais o conhecimento científico é socializado, propomo-nos a estudar o que acontece quando a voz de enunciadores citados é utilizada para compor o texto de divulgação científica (doravante DC). Trata-se da voz (um enunciador citado) responsável pelos enunciados. Esse fenômeno é designado, aqui, como Responsabilidade Enunciativa (doravante RE). Uma das idiossincrasias da comunicação da ciência na mídia é, justamente, o chamado discurso relatado, que reflete um processo de reformulação ${ }^{2}$ do discurso científico (AUTHIER-REVUZ, 1998) em um novo domínio (o midiático). O produtor textual, nesse contexto, com certa frequência, atribui a uma fonte científica o conteúdo veiculado, normalmente para "validar ou credibilizar determinado conteúdo", como afirma Cortez (2011, p. 89). As funções discursivas desse fenômeno enunciativo merecem ser mais bem averiguadas, para que se possa compreender os cálculos que o produtor textual faz ao assumir ou delegar predicações para compor um texto estrategicamente eficaz; isso justifica nosso estudo.

O objetivo geral deste artigo é investigar as estratégias de Responsabilidade Enunciativa (do nível enunciativo, referente às vozes do texto) em uma reportagem de DC, verificando a maneira pela qual as diferentes formas de (des)responsabilização encaminham o pensamento do enunciatário sobre os fatos apresentados na reportagem, conforme o projeto comunicativo do Locutor/Enunciador (L1/E1) ${ }^{3}$. Fazemos isso

\footnotetext{
${ }^{1}$ O grupo de pesquisa CCELD (Comunicação da Ciência: Estudos Linguístico-discursivos) pertence ao Programa de Pós-Graduação em Linguística Aplicada da Universidade do Vale do Rio dos Sinos (UNISINOS) e é coordenado pela Prof ${ }^{a}$. Dr ${ }^{a}$. Maria Eduarda Giering. A equipe de pesquisa toma como objeto os discursos de comunicação da ciência que circulam em diferentes esferas.

${ }^{2}$ Nessa concepção, basilar para o presente trabalho, a comunicação da ciência no contexto midiático implica reformular o discurso científico, recontextualizando-o, e não traduzir uma informação original. A reformulação pressupõe a existência de distintas esferas de atuação (a esfera do cotidiano e a esfera da ciência, no mínimo), que se entrecruzam na situação de midiatização da ciência. Divulgar a ciência é recontextualizar o mundo da ciência, alocando-o em novas configurações, de maneira distinta ao ato enunciativo de origem, ainda assim passível de identificação.

${ }^{3}$ L1/E1 é a formulação empregada para caracterizar a coincidência entre, de um lado, o produtor do enunciado (L1) focalizado e, de outro lado, o enunciador (E1), que é uma posição enunciativa, âmbito de responsabilização e ponto de vista - os números coincidentes indicam um autodialogismo, como diriam Koch e Cortez (2015). No presente trabalho, a sigla L1/E1 designa a instância de enunciação correspondente ao jornalista, pessoa que assina a reportagem. Além da responsabilização por um enunciado autodialógico, é possível que o locutor de um dado discurso seja a via de proferimento de pontos de vista de terceiros, com
} 
analisando as marcas linguísticas do texto, conforme determinados procedimentos de análise qualitativa (a serem esclarecidos na seção 4 do presente trabalho). Nossa pergunta de pesquisa é: De que maneira a assunção ou não assunção de Responsabilidade Enunciativa atua para construir os sentidos pretendidos pela instância de produção da reportagem? A esse ponto procuramos chegar.

Para explorar o fenômeno da Responsabilidade Enunciativa, adotamos, aqui, os postulados teóricos da Análise Textual dos Discursos (doravante ATD), elaborada por Adam (2011), e de Guentchéva (1994; 1996), que desenvolve a noção de mediativo (também denominada, em nosso trabalho, discurso indireto mediado); essa abordagem teórica será elucidada na seção 3 do presente artigo. Mas, para começar, situaremos o problema da Responsabilidade Enunciativa em seu contexto mais abrangente, na seção 2, a seguir.

\section{A DIVULGAÇÃO CIENTíFICA MIDIÁTICA E O ATO DE (DES)RESPONSABILIZAÇÃO}

Nas práticas da imprensa, o problema da Responsabilidade Enunciativa regularmente se instaura nos compromissos éticos de tratamento da informação, obrigando os jornalistas a adotar recursos linguísticos que permitam acautelar o teor das asserções, equilibrando-se num espaço desresponsabilizador, para evitar inconvenientes de ordem jurídica.

No discurso de DC, o papel do divulgador de ciência inclina-se para uma autoria mais compartilhada, decorrente do esforço de validação, conforme mostra Bueno (2011). O levantamento de fontes e a remissão aos "protagonistas" da informação científica (médicos, pesquisadores etc.) são uma forma mediada de obtenção da informação, como esclarece Bueno (2011).

\footnotetext{
O divulgador científico, de per si, a não ser que tenha sido guindado à posição de colunista, ou seja, ele próprio um especialista em uma determinada área, não responde sozinho pelas informações que veicula, baseando-se em pessoas ou materiais (artigos, documentos etc.) que as validam. (BUENO, 2011, p. 55).
}

As estratégias de distanciamento de um dito podem dar-se de muitas maneiras, conforme indica a literatura (NEVES, 2006; NEVES; OLIVEIRA, 2007), já que a realidade factual noticiada é acessada por dizeres de testemunhas (uma gama de instâncias, mais ou menos institucionalizadas, que, uma vez potencialmente envolvidas com o tema ou com C\&T, são entrevistadas ou convocadas à fala, a dar algum depoimento, tais como especialistas científicos, representantes de institutos de pesquisa ou órgãos governamentais, políticos ou cidadãos em geral). De um lado, podem aparecer, nos textos, recursos de envolvimento com o conteúdo (por meio de adjetivos, por exemplo), e, de outro, pode haver procedimentos de distanciamento do conteúdo, como

diferentes intenções. Neste caso, fica L1/E2. E2, então, é o enunciador segundo, aquele que é convocado a falar, trazido ao texto por L1. Se o outro locutor estivesse falando e assumindo um ponto de vista determinado teríamos L2/E2. As convenções de sigla se dão em conformidade com Koch e Cortez (2015). 
no apelo a construções interrogativas (NEVES, 2006). Dentre as estratégias de distanciamento, pela classificação de Neves (2006, p. 1457), o produtor textual pode realizar a atribuição direta a uma fonte enunciativa, que indica que "o enunciador não adquiriu diretamente o conhecimento, mas sim indiretamente", o que o leva a citar essa fonte.

Antes de elucidarmos as ferramentas teórico-metodológicas da ATD para descrição da Responsabilidade Enunciativa (tema da seção 3 deste artigo), é importante situarmos o contexto mais amplo da atividade linguageira na qual se inscrevem os enunciadores que assumem seus ditos, conforme seus propósitos, na divulgação científica midiática.

Como mostra Charaudeau (2016), a midiatização da ciência - também chamada de divulgação científica midiática (doravante DCM), neste trabalho - cumpre uma dupla finalidade: informar e/ou explicar questões de ciência e, também, captar o seu público, suscitando seu interesse pela matéria. No discurso de DCM, ao locutor cabe empregar recursos que visem à informação (como metáforas que facilitem o entendimento do conteúdo) e outros que objetivem espetacularizar a informação, para chamar a atenção do público-alvo.

O produtor textual é influenciado, então, pelas demandas do contrato de comunicação de midiatização da ciência (CHARAUDEAU, 2016), tendo que manejar seu discurso levando em conta as restrições desse contrato, a saber: restrição de seriedade (apresentando provas daquilo que se diz); restrição de emocionalidade (procurando provocar os afetos do público, para fazê-lo consumir a informação); restrição de inteligibilidade (utilizando estratégias didáticas de explicação) e restrição de visibilidade (tornando mais concretos e mais próximos do leitor os conceitos da ciência) (CHARAUDEAU, 2016).

No que concerne à sua dialogia, para Moirand, Touré e Ribeiro (2016), o fato de a divulgação científica ser intermediária entre a atividade erudita, a atividade dos especialistas, e a esfera dos leitores comuns convoca um comunicador mediador, um terceiro homem, "especialista dessa mediação linguageira". Podendo ser um jornalista, esse mediador empregará sequências relatadas, tendentes a ser argumentos de peso (MOIRAND; TOURÉ; RIBEIRO, 2016, p. 148). Com o discurso relatado, demarca-se a seriedade do órgão de informação, de modo que ele consegue transmitir a imagem de "bom transmissor do conhecimento científico" (CHARAUDEAU, 2016, p. 555). Por conseguinte, a Responsabilidade Enunciativa constitui uma estratégia de seriedade, no nosso entender, pois as referências científicas (lê-se especializadas) são determinações da restrição de seriedade, do contrato de midiatização da ciência (CHARAUDEAU, 2016).

A encenação das sequências relatadas poderá permitir ao produtor textual subordinar-se aos pontos de vista dos experts ou marcar distanciamento em relação a eles, promovendo a representação dessas responsabilidades.

\section{RESPONSABILIDADE ENUNCIATIVA E PONTO DE VISTA}


Neste estudo, investigamos a Responsabilidade Enunciativa ou Ponto de Vista ${ }^{4}$ sob a ótica da ATD, elaborada pelo linguista francês Jean-Michel Adam (2011) como um subdomínio da Linguística Textual.

O modelo teórico proposto por Adam (2011) oferece elementos para o entendimento do texto como uma prática discursiva que pode ser examinada à luz de determinados planos ou níveis de análise: o nível sequencial-composicional, o enunciativo, o semântico e o argumentativo.

No presente trabalho, detemo-nos no nível enunciativo, que se preocupa com as vozes do texto e objetiva analisar se os enunciados são ou não assumidos pelo locutornarrador (ADAM, 2011, p. 115) e quais as implicações dessa (não) assunção da responsabilidade enunciativa na construção de seu discurso e de seus propósitos comunicativos.

A RE é uma das dimensões da proposição-enunciado, unidade elementar mínima da ATD. Tal unidade é constituída, na verdade, de três dimensões que se complementam, a saber: a dimensão enunciativa, o conteúdo referencial e o componente argumentativo. Como, no nosso caso, o foco é a Responsabilidade Enunciativa, procuramos reconhecer quem é o sujeito (construído e modelado na enunciação) que se responsabiliza pelo PdV locucionado nas asserções discursivas.

A RE não se separa de um PdV, e ambos se situam no âmbito da polifonia, conforme Adam (2011). A RE é, pois, o fenômeno que permite aferir o grau de engajamento do locutor em um ato de enunciação. Conforme Passeggi et al. (2010, p. 299), a RE "consiste na assunção por determinadas entidades ou instâncias do conteúdo do que é enunciado, ou na atribuição de alguns enunciados ou PdV a certas instâncias".

Adam (2011) considera o locutor como a pessoa que fala, a pessoa física responsável pela enunciação. Sempre que o enunciador assume a responsabilidade pelo dizer, locutor e enunciador se mesclam (tem-se L1/E1); quando o enunciador se exime da responsabilidade, locutor e enunciador constituem entidades distintas, seja porque o ponto de vista é atribuído a outrem (a um enunciador segundo, E2 ${ }^{5}$ ), seja porque são anônimos, constituindo-se em pontos de vista $(\mathrm{PdVs})$ ligados à opinião comum. Nesse sentido, é possível ao locutor-narrador marcar um distanciamento em relação ao PdV proferido, ora adotando estratégias para eximir-se da responsabilidade pelo que é dito, ora delegando-a ao PdV de um outro enunciador e a uma outra fonte do saber, ora delegando-a a um PdV anônimo. Nesses casos, teremos a situação de desengajamento do locutor em relação ao conteúdo predicado, o que significa não assumir o PdV. Entretanto, se for conveniente aos seus propósitos, o locutor pode atribuir a si próprio certa enunciação, assumindo o PdV.

Entre as categorias linguísticas que assinalam a RE, consoante Adam (2011), têmse: índices de pessoas (notadamente os pronomes); dêiticos espaciais e temporais; tempos verbais (localizadores da posição e da perspectiva dos enunciadores, como o uso do

\footnotetext{
${ }^{4}$ No presente artigo, utilizaremos Responsabilidade Enunciativa e Ponto de Vista como equivalentes.

${ }^{5}$ Registre-se, então, que E2 é concebido como uma fonte, o enunciador segundo, a origem do saber, não constituindo, necessariamente, uma pessoa física que diz. Isso permite que o locutor focalize objetos de discurso não apenas em relação a si, mas também em relação ao PdV de outros (KOCH; CORTEZ, 2015).
} 
condicional); indicações de quadros mediadores; indicações de modalização autonímica, entre outras.

O divulgador científico, no corpus de nossa análise, avoca a voz de outros sujeitos (de especialistas no assunto), de tal modo que a instauração de quadros mediadores, ao longo do texto, é uma ação comum. Concentramos nossa atenção nas marcas de quadros mediadores, cuja conceituação Adam (2011) remete à da pesquisadora Zlatka Guentchéva, embora assuma que as citações (atribuições de um dizer a uma fonte enunciativa segunda) ocorrem por discurso direto, discurso indireto e discurso indireto mediado; os dados empíricos que coletamos pertencem a essas três unidades de responsabilização enunciativa. Os quadros mediadores são os arranjos linguísticos que assinalam o afastamento ou engajamento do enunciador diante de conteúdos transmitidos no texto (LOURENÇO; RODRIGUES, 2013), e o procedimento metodológico de identificação desses arranjos é apresentado na seção 4 (Metodologia).

Adam (2011) vale-se, em seus estudos sobre a RE, de Guentchéva (1994, 1996), que desenvolve a noção de categoria gramatical do mediativo, a qual permite marcar linguisticamente uma atitude de distanciamento ou não engajamento do enunciador diante das informações expressas, uma vez que elas lhe chegaram de forma mediada.

Guentchéva (1994, 1996) afirma que o locutor emprega o mediativo, em seu enunciado, para inscrever linguisticamente a procedência da informação transmitida, isto é, marcar não ser ele a fonte da informação. O locutor indica em seu enunciado a origem do saber que esse enunciado deve comunicar. O estudo de Lourenço e Rodrigues (2013, p. 79), a propósito, embasado em Guentchéva, levanta alguns dos processos gramaticais que viabilizam o mediativo: "as modalidades (poder, crer, achar, parecer etc.), os advérbios de frase (aparentemente, alegadamente, certamente), as locuções conjuntivas conformativas (de acordo com..., segundo...), os verbos de dizer e de ação metalinguística", entre outras.

Mais do que permitir identificar o enunciador responsável pelo enunciado, a RE instala a problemática da assunção do conteúdo de um enunciado e dos pertencimentos a certo modo de enxergar e apreender o conteúdo proposicional. Um conteúdo perceptivo pode ser representado de variadas maneiras, a depender do projeto de dizer do locutor, o que realça a centralidade do sujeito, fonte de uma direção discursivo-argumentativa (CORTEZ, 2011; KOCH; CORTEZ, 2015).

É mister, então, que examinemos a RE no modo como o enunciado é construído; se atribuído a alguém, que tipo de representação do discurso do outro L1/E1 promove? Podemos investigar, desse modo, o discurso relatado como peça da encenação das posições enunciativas.

Entendemos que essa orientação argumentativa se evidencia em marcas linguísticas presentes no cotexto, nas redondezas das indicações de quadro mediador - mesmo que o produtor textual procure conscientemente se distanciar das asserções. Mais do que isso, a argumentação incide sobre os quadros mediadores, provocando efeitos de sentido sobre o que é dito nesses quadros, como mostraremos na seção de análise dos dados (seção 5).

O teor argumentativo não se depreende apenas da proposição (de seu estatuto temático), mas, sobretudo, da combinação entre o segmento informacional e a operação 
argumentativa que encadeia ou introduz tal segmento. De acordo com Koch e Cortez (2015, p. 37-38),

\begin{abstract}
De forma velada ou explícita, L1/E1 como enunciador principal de um texto, seja como agente do dizer ou da representação de um conteúdo perceptivo atribuído a outrem, é responsável pelas escolhas lexicais, pela seleção das informações, das percepções e das palavras enquanto locutor/enunciador. Tal ação evidencia um trabalho sobre o conteúdo do discurso, inserindo o sujeito produtor do texto nessa prática discursivo-argumentativa. (KOCH; CORTEZ, 2015, p. 37-38, grifos nossos).
\end{abstract}

As propostas de sentido atribuídas a E2 por L1, na reportagem que analisamos neste artigo, são alocadas em certos regimes de inteligibilidade, por intermédio de operadores argumentativos ("nada menos", "até mesmo", entre outros). Conjunções, modalizadores e locuções adverbiais, por exemplo, utilizados na contextualização dos dizeres atribuídos, nas situações de RE, compõem o repertório lexical que dá, a nossos olhos analíticos, orientação argumentativa ao texto.

Aclarados os fundamentos teóricos que viabilizam a análise da Responsabilidade Enunciativa em nosso corpus, passemos agora para a descrição dos procedimentos metodológicos adotados em nossa investigação.

\title{
4 METODOLOGIA
}

Elegemos, como corpus de análise, enunciados de uma reportagem de DCM publicada na revista Superinteressante (na edição de número 335, de julho de 2014). O título da reportagem é $A$ verdade sobre o glúten, assinada por Robson Pandolfi.

Com a premissa de que RE está presente no discurso de DCM, debruçamo-nos a verificar, na reportagem, outras idiossincrasias que emergem desse procedimento linguístico-discursivo. Contudo, no presente artigo, não analisaremos todas as ocorrências de responsabilização enunciativa da reportagem. São focalizados apenas alguns excertos da reportagem, correspondentes às ocorrências que consideramos mais significativas para caracterizar a assunção dos pontos de vista.

Para chegarmos aos resultados alcançados, as etapas percorridas foram as seguintes:

1) Levantamento das ocorrências de discurso indireto, discurso direto e discurso indireto mediado (mediativo) na reportagem, por meio da localização de marcas de citação (direta ou indireta), em construções como "segundo", "para" e aspas citativas, a exemplo.

2) Descrição das ocorrências de discurso indireto, discurso direto e discurso indireto mediado (mediativo) na reportagem, com o intento de averiguar os pontos de vista que esses enunciados imprimem e suas nuanças semânticas.

3) Identificação das ocorrências de RE em excertos, que correspondem a cada parágrafo da reportagem - apenas os parágrafos que apresentam os dados de RE selecionados no primeiro levantamento. Esse procedimento objetivou demarcar o cotexto 
em que se encontra cada ocorrência de RE, seja ela de discurso direto, indireto ou de mediativo.

4) Segmentação dos enunciados de cada excerto. Do número 1 em diante, temos a sinalização do segmento informacional; ou seja, cada número assinala o começo de uma "frase", por assim dizer, que sempre finaliza no ponto final seguinte.

5) Descrição e análise de alguns dos excertos (aqueles considerados os mais representativos do fenômeno de RE), observando-se as marcas de denotação da (não) assunção da RE pelo produtor da reportagem. Assim, procedemos à identificação da atribuição ou assunção de pontos de vista, para posterior análise da maneira como esses pontos de vista são representados.

6) Análise qualitativa dos excertos, que prevê a descrição das várias formas de desresponsabilização ou de assunção de pontos de vista pelo locutor (L1/E1). Verificamos, nesse caso, os recursos empregados por L1/E1 para semantizar os pontos de vista (de enunciadores segundos, a quem denominamos E2) na reportagem, a saber: codificação da fonte enunciativa ${ }^{6}$, verbos ou conjunções escolhidos para delimitar a citação, marcas de atenuação ou de fiabilidade conferidos aos conteúdos predicados (por meio de escolhas linguísticas de toda sorte).

Na sequência, propomo-nos a exibir alguns resultados obtidos, tecendo comentários analíticos acerca das ocorrências de RE.

\section{ANÁLISE DOS DADOS}

Examinaremos três excertos da reportagem $A$ verdade sobre o glúten, procurando mostrar (i) o funcionamento da representação de dois pontos de vista que estão em disputa na reportagem e (ii) a orientação argumentativa que é encaminhada a partir dessa representação constatada. O fim discursivo da reportagem examinada é informar os impactos da ingestão de glúten na saúde humana.

Interpretando a reportagem, localizamos duas perspectivas sobre o assunto desenvolvido (impactos do glúten na saúde humana). Faremos referência a essas duas perspectivas, ao longo desta seção, da seguinte maneira: PdV1 (=refere-se ao posicionamento a favor do melhoramento genético e incrédulo em relação a malefícios tão drásticos) e PdV2 (=refere-se à crítica ao melhoramento do trigo e ao consequente consumo de glúten).

Para analisar a representação-encenação dos PdVs, tivemos de reconhecer o modo como o locutor da reportagem trata essas duas perspectivas sobre o glúten (atribuídas a certos enunciadores). Isso implicou, em primeiro lugar, identificar os mecanismos linguístico-discursivos de demarcação das fontes enunciativas e indicar propriamente os

\footnotetext{
${ }^{6}$ Utilizamos o negrito nas passagens correspondentes aos excertos para realçar as marcas linguísticas que são foco de nossa análise. Às vezes, as unidades em negrito se referem à codificação da fonte enunciativa do conteúdo apresentado (quando se informa quem é o responsável pelo dito), mas, em alguns momentos, serão realçadas outras construções linguísticas relevantes, como modalizadores e verbos que denotam efeitos de sentido e procedimentos argumentativos de nosso interesse, facilitando, assim, o registro dos dados coletados e o acompanhamento de nosso percurso de análise na seção 5.
} 
conteúdos que transmitem sobre a questão do glúten. Em segundo lugar, observamos as representações sobre os pontos de vista, porque eles são semantizados estrategicamente pela instância de produção da reportagem.

O primeiro excerto sobre o qual fazemos algumas considerações analíticas será designado Excerto 1. Numeramos os excertos nessa sequência, a partir do 1, o que não significa que um apareça imediatamente após o outro na reportagem da revista; são, na verdade, partes diferentes da mesma reportagem.

$\mathrm{O}$ Excerto 1 pertence à primeira seção do texto principal da reportagem $A$ verdade sobre o glúten, que tem 4 seções. Esse excerto pressupõe alguns conhecimentos para que haja a compreensão do nosso relato da análise. Convém explicitá-los: o Excerto 1 expõe algumas particularidades do trigo com glúten ao descrever os benefícios dessa composição. No cotexto que antecede o Excerto1, já foi explicado que o trigo sofreu diversas modificações ao longo do tempo, muitas delas naturais ${ }^{7}$. Também já é considerada uma informação dada a de que, na segunda metade do século 21 , impulsionaram-se muitos cruzamentos para que se gerassem tipos de trigo mais resistentes. Essas informações todas são fornecidas a priori. Feitos os esclarecimentos, passemos aos comentários analíticos.

\section{Excerto 1}

(1) E isso foi uma coisa boa, tanto que uma das características mais valorizadas no trigo é a chamada "força de glúten", que ajuda muito na produção de pães. (2) "É ela que deixa o pão fofo, alto e bonito. Se não tiver uma força de glúten mínima, o pão não cresce", explica o pesquisador Eduardo Caeirão, que trabalha com melhoramento genético na Embrapa Trigo. (PANDOLFI, 2014, p. 31, grifo nosso).

Por meio desse excerto, L1/E1dá espaço para a valorização positiva da produtividade do trigo que prescinde de glúten. "Isso" (do segmento 1) faz referência aos melhoramentos do trigo (que resultaram em glúten), descritos em enunciados antecedentes.

Essa diferenciação entre bom e ruim é feita por L1/E1 - assumidamente pelo próprio produtor textual, mescla de locutor e de enunciador). Em vez de distanciamento, portanto, L1/E1 envolve-se com o conteúdo. Isso é observável na adjetivação ("coisa boa"). O envolvimento também se percebe pelo intensificador "muito" em "ajuda muito na produção de pães" (segmento 1), que pressupõe, vale ter em mente, a fabricação de pães como algo útil (bom) para a as pessoas.

$\mathrm{Na}$ primeira parte da proposição-enunciado, L1/E1 engaja-se em relação ao PdV. Mas, no segmento informacional 2, insere a declaração do cientista Eduardo Caeirão, pesquisador da Embrapa Trigo, já marcada com uso de aspas - essa declaração está negritada no Excerto 1. Observamos que essa declaração é (i) um discurso relatado direto, pois é reproduzido um discurso alheio; (ii) é direto, porque supostamente expõe de modo

\footnotetext{
${ }^{7}$ Fazemos este esclarecimento, porque tal conhecimento não estará tão explícito nos excertos aqui analisados e corresponde a um requisito para a compreensão das asserções que estão presentes nos excertos. Como não contemplamos, no presente artigo, a totalidade da reportagem como objeto de análise, julgamos importante fazer essas ressalvas.
} 
fidedigno o que foi dito no discurso-fonte, o que é sinalizado pelas aspas ${ }^{8}$. Disto, concluise que L1/E1 exime-se da responsabilidade pelo que é dito, atribuindo-a a outra fonte epistêmica.

Dada essa identificação, procedemos a uma análise mais acurada.

L1/E1 busca sinalizar que, a partir das aspas, ele não se responsabiliza pela mensagem. Contudo, "ela" (no segmento 2), anáfora de "a força de glúten", indica que a mensagem do segmento 2 está estritamente ligada ao PdV já expresso no cotexto à esquerda, além de que a declaração do pesquisador é uma explicação adicional, que reformula algo preexistente (já assumido por L1/E1, ao que parece): a força de glúten ajuda na produção de pães.

A citação, a nosso ver, apenas encena (simula) o distanciamento de L1/E1 em relação ao conteúdo dito por $\mathrm{E} 2$, sem que haja afastamento efetivo. A citação direta (discurso direto) serve para fortalecer a mensagem que é já assumida por L1/E1.

$\mathrm{Na}$ sequência, verificaremos alguns pontos de RE no Excerto 2, o qual traz um contraponto à visão expressa no Excerto 1, pois difunde o PdV2 (crítica ao melhoramento do trigo e ao consequente consumo de glúten).

\section{Excerto 2}

(1) Mas, para alguns médicos, esse processo de desenvolvimento do trigo pode ter ido longe demais, e estar causando efeitos ruins. (2) "O trigo foi esticado, costurado e cortado e recosturado, para transformar-se em algo totalmente singular, quase irreconhecível quando comparado com o original, e mesmo assim atendendo pelo mesmo nome: trigo", diz o cardiologista americano William Davis, cujo livro Barriga de Trigo ficou 50 semanas entre os mais vendidos nos EUA. (PANDOLFI, 2014, p. 31, grifo nosso).

O segmento informacional 1 do Excerto 2 é uma contraposição aos elogios que o trigo modificado vinha recebendo até então. Essa nova visão, no Excerto 2, é inaugurada já com um enunciado relatado. A marca do mediativo é a locução conformativa "para alguns médicos" (negritada no segmento 1 do Excerto 2). A locução evidencia que a informação disponibilizada foi obtida de maneira mediada.

L1/E1, apesar da contraposição feita por "alguns médicos" (fonte enunciativa codificada no segmento1) e, mais adiante, pelo cardiologista William Davis, manifesta apenas suspeita em relação à possibilidade de o trigo com melhoramentos ter acarretado efeitos ruins. Esse sentido de possibilidade é engendrado pelo verbo "pode": "o processo de desenvolvimento do trigo pode ter ido longe demais" (segmento informacional 1).

Observemos mais atentamente tal excerto, examinando as marcas de desreponsabilização, próprias de mediativo. Primeiro, comentamos o emprego de "para alguns médicos"; depois, a utilização do verbo "pode".

A primeira marca de mediativo é "para alguns médicos". Essa responsabilização é coerente com o que L1/E1 assumiu em enunciados antecedentes do texto, nos quais avaliou positivamente as modificações do trigo - o trigo modificado é elogiado em termos

\footnotetext{
${ }^{8}$ Usam-se aspas e itálico nas palavras científicas, aquelas do outro discurso (palavras estrangeiras), identificadas com o discurso-fonte, o que pressupõe que exista, na tessitura enunciativa, a palavra cotidiana, concebida como distante do conhecimento científico, conforme elucida Authier-Revuz (1998, p. 77).
} 
de produtividade e gosto (vide Excerto 1). Já a mensagem do Excerto 2 consiste em desaprovar o trigo modificado. Portanto, L1/E1 distancia-se dessa perspectiva, por não ser aquela com a qual compactua.

A fonte não é apresentada muito claramente. Mas o sintagma nominal de valor genérico "alguns médicos", devido ao pronome "alguns", desempenha, a nosso ver, um importante papel informativo e argumentativo. Ele seria uma maneira de o enunciador enfatizar que não são todos os médicos que consideram o trigo modificado algo ruim, mas só alguns. É como se o enunciador avisasse: nem todos os médicos pensam assim, a crença não é unânime. O pronome indefinido "alguns" é um recurso pragmático-discursivo que tira da proposição o teor de "verdade absoluta", enfraquecendo o PdV2 (crítica ao melhoramento do trigo e ao consequente consumo de glúten).

Temos uma segunda marca de desresponsabilização do dito, que é a modalização que o enunciado sofre por meio do "pode ter" em "esse processo de desenvolvimento do trigo pode ter ido longe demais". Entendemos que L1/E1 reforça, com essa operação modal, o caráter hipotético do conteúdo mobilizado no segmento 1. O poder, nessa locução verbal, comporta-se como modalizador epistêmico quase-asseverativo, segundo classificação de Castilho e Castilho (2002). Por meio desse modal, L1/E1 exprime validação parcial, estabelecendo que o estado de coisas predicado é algo apenas plausível, não certo. Na sequência, no segmento informacional 2, do mesmo excerto, L1/E1 insere o posicionamento de um desses "alguns médicos": o cardiologista William Davis. Concentramo-nos, agora, nessa citação.

(2) "O trigo foi esticado, costurado e cortado e recosturado, para transformar-se em algo totalmente singular, quase irreconhecível quando comparado com o original, e mesmo assim atendendo pelo mesmo nome: trigo", diz o cardiologista americano William Davis, cujo livro Barriga de Trigo ficou 50 semanas entre os mais vendidos nos EUA. (PANDOLFI, 2014, p. 31, grifo nosso).

Com a apresentação clara da fonte enunciativa, no segmento informacional 2, L1/E1 se distancia do fato relatado (de que o trigo foi modificado a ponto de ficar quase irreconhecível), que é constituído de um argumento-prova direcionado à tese defendida pelo cardiologista (tese referente ao PdV2).

Trata-se de um discurso relatado direto. Faz-se referência direta ao que William Davis afirmou outrora, com uma suposta reprodução fiel do seu dizer, conforme sinalizam as aspas citativas. L1/E1 exime-se da responsabilidade, conferindo-a ao cardiologista.

No segmento informacional 2, não verificamos modalização (como ocorre no segmento 1), mas apenas reprodução aparentemente fiel dos dizeres de uma fonte segunda, a qual assume o PdV de que o trigo sofreu várias modificações e faz uma crítica quanto a isso.

O Excerto 3, sobre o qual falaremos a partir de agora, corresponde, na reportagem, ao parágrafo imediatamente subsequente ao parágrafo do Excerto 2. Então, logo depois de avocar o cardiologista William Davis, L1/E1 começa um novo parágrafo ainda se referindo à teoria defendida por Davis. 


\section{Excerto 3}

(1) Essa teoria, de que o melhoramento genético do trigo possa ter criado um monstro, é apenas uma teoria - e bastante questionada pelos pesquisadores da área. (2) Isso porque os cruzamentos genéticos ocorrem há milênios e, em alguns casos, acontecem de forma natural, sem a ação do homem. (3) Não há comprovação científica de que esse processo tenha modificado a forma como o trigo é digerido. (4) "Não há um só sistema no organismo que não seja afetado pelo trigo", ataca Davis. (5) "Da fadiga à artrite, do desconforto gastrointestinal ao ganho de peso, todos [esses males] têm como origem o alimento, de aparência inocente, que cada um de nós come todas as manhãs", acredita. (6) Por essa tese, o trigo pode estar nos fazendo mal - e ser o grande responsável pela epidemia de obesidade no mundo [...]. (PANDOLFI, 2014, p. 31, grifo nosso).

L1/E1 desenvolve alguns comentários sobre a declaração de Davis, que representa o PdV2 (dos que defendem que o trigo modificado faz mal). Esses comentários de L1/E1 estão presentes nos segmentos 1, 2, 3 e 6 do Excerto 3. Mas precisamos examinar melhor este Excerto 3, a começar pelas escolhas lexicais realçadas por nós no trecho.

Em primeiro lugar, classificamos as designações negritadas como discurso indireto, porque se está predicando o que a teoria defende, sem dizer "de acordo". Em segundo lugar, a nomeação "essa teoria", que introduz o parágrafo, resume uma porção maior do cotexto antecedente, desempenhando uma função sumarizadora e avaliativa (CONTE, 2003). A avaliação é observada sobretudo na denominação "apenas uma teoria", empregada também no segmento 1. Com essa escolha, o produtor salienta que as ideias do PdV2 não são uma verdade, mas apenas plausíveis.

No rótulo avaliativo "apenas uma teoria" (no segmento 1 do Excerto 3), o advérbio "apenas" atenua o valor de asserção, conferindo um grau de assertividade baixo à declaração de L1/E2 ("alguns médicos" e William Davis). L1/E1, aliás, afirma que a teoria dos médicos é "bastante questionada pelos pesquisadores da área” (segmento 1), eximindo-se da responsabilidade, pois são outros cientistas que discordam de Davis.

Na sequência (a partir do segmento 4), aciona-se mais um discurso relatado, do qual L1/E1 explicitamente não toma parte. Após dizer, no segmento 2, que os cruzamentos genéticos são um fenômeno natural (e, talvez por isso, não sejam um problema), L1/E1 avoca Davis para inserir uma contraposição à atenuação de sua teoria (questionada por “pesquisadores da área”). Vejamos essa segunda parte do Excerto 3, na sequência.

(4) "Não há um só sistema no organismo que não seja afetado pelo trigo", ataca Davis. (5) "Da fadiga à artrite, do desconforto gastrointestinal ao ganho de peso, todos [esses males] têm como origem o alimento, de aparência inocente, que cada um de nós come todas as manhãs", acredita. (PANDOLFI, 2014, p. 31, grifo nosso).

$\mathrm{Na}$ atribuição de fala desse enunciado, expressa-se basicamente o mesmo PdV do Excerto 2, do qual L1/E1 se afasta. Desse afastamento resulta o discurso relatado direto no segmento 4. O responsável pela declaração é o mesmo cardiologista, um dos defensores do PdV2.

O verbo de dizer eleito na mediação epistêmica merece atenção. "Atacar" pode ter um sentido bélico, que transmite a ideia jogo de forças. Nessa acepção, "atacar” guarda afinidade com verbos como enfrentar, censurar, criticar. William Davis estaria sendo 
representado como um dos oponentes no jogo de forças. Essa é uma conotação coerente com o dialogismo que L1/E1 pretende criar no simulacro do texto, alicerçado na oposição de ideias.

A descrença do L1/E1 em relação ao PdV2, de William Davis, é marcada linguisticamente. Os PdVs, a propósito, ficam bem demarcados no texto ${ }^{9}$. L1/E1 mostra ter postura diferente daqueles outros enunciadores (os médicos, e, incluindo aí, William Davis).

Além de o primeiro segmento do Excerto 3 apresentar a teoria (do cardiologista) com um tom de desconfiança, os segmentos 4 e 5 também o fazem. O segmento 5, na verdade, é a continuidade do raciocínio de Davis, em que ele diz que os alimentos modificados têm impactado o corpo humano.

Focalizemos mais detidamente o segmento 5, agora. Esse segmento é finalizado com o verbo "acreditar", que faz o fechamento da citação - é um discurso direto como o segmento 4.

No segmento 5, L1/E1 constrói a mediação epistêmica, mas atribuindo à fala de Davis um baixo grau de assertividade. L1/E1 não assevera nada, não afirma, não explica; E2 apenas acredita - pela manipulação que L1 faz do discurso alheio -, o que está na ordem do crer, do cogitar. A título de comparação, convém lembrar que, no PdV expresso no Excerto 1, que contou com a atribuição da fala a Eduardo Caeirão, o discurso relatado apresenta o verbo "explicar", que pressupõe que o enunciador responsável (E2), o sujeito que explica, tem competência e legitimidade para explicar, o que se diferencia do que estamos examinando agora. No Excerto 3, que estamos analisando neste momento, a fonte enunciativa apenas acredita. Então, o conteúdo da citação é visto como algo do domínio do não certo.

A baixa assertividade, junto com a não adesão de L1/E1 ao PdV2, é justamente uma elaboração psico-sócio-linguageira de L1/E1. Tal operação de construção do PdV se dá, ainda, por intermédio da modalização epistêmica quase-asseverativa de "pode estar", empregada no enunciado que sucede o segmento 5. Observemos este novo enunciado (segmento 6).

(6) Por essa tese [de William Davis], o trigo pode estar nos fazendo mal - e ser o grande responsável pela epidemia de obesidade no mundo [...]. (PANDOLFI, 2014, p. 31, grifo nosso).

Esse segmento 6 é um discurso relatado mediado, devido ao afastamento de L1/E1 do conteúdo proposicional. L1/E1 apenas sublinha a possibilidade um tanto longínqua de a tese dos médicos ser uma verdade.

A seguir, mostramos uma sistematização de nossa análise, caracterizando as posturas enunciativas de L1/E1 decorrentes da assunção ou não dos pontos de vista.

\footnotetext{
${ }^{9}$ Temos o operador argumentativo "mas", que introduz o parágrafo do Excerto 5, "mas para alguns médicos [...], mostrando que a visão dos médicos se contrapõe àquela apresentada no cotexto precedente. Outro exemplo são as várias marcas anafóricas (como "essa teoria") que destacam o distanciamento de L1/E1 em relação ao PdV alheio.
} 
L1/E1 esforça-se para representar o PdV2 como algo afastado da certeza, ou cuja verdade está fora de questão. Com isso, ele se engaja ao PdV1 (assumindo-o) - o que aliás é observável em outros Excertos da reportagem, mas que não foram contemplados no recorte apresentado neste artigo. O Quadro 1 (a seguir) apresenta um resumo dos resultados da análise.

\section{Quadro 1 - Quadro-resumo das responsabilidades e posturas ${ }^{10}$}

\begin{tabular}{|c|c|}
\hline Excerto & Tipo de engajamento ou relação entre L1/E1 e E2 \\
\hline $\begin{array}{l}\text { Excerto } 1 \\
\text { (1) E isso foi uma coisa boa, tanto que uma das } \\
\text { características mais valorizadas no trigo é a chamada } \\
\text { "força de glúten", que ajuda muito na produção de } \\
\text { pães. (2) "É ela que deixa o pão fofo, alto e bonito [...]" } \\
\text { explica o pesquisador Eduardo Caeirão, que trabalha } \\
\text { com melhoramento genético na Embrapa Trigo. }\end{array}$ & $\begin{array}{l}\text { Envolvimento de L1/E1 com o que E2 afirma - E1 } \\
\text { inicia o parágrafo afirmando que a "força de glúten" é } \\
\text { positiva. O discurso direto do segmento } 2 \text { é empregado } \\
\text { para sustentar essa visão (PdV1). L1/E1 adere ao PdV1. }\end{array}$ \\
\hline $\begin{array}{l}\text { Excerto } 2 \\
\text { (1) Mas, para alguns médicos, esse processo de } \\
\text { desenvolvimento do trigo pode ter ido longe demais, e } \\
\text { estar causando efeitos ruins. (2) "O trigo foi esticado, } \\
\text { costurado e cortado e recosturado, [...]", diz o } \\
\text { cardiologista americano William Davis, cujo livro } \\
\text { Barriga de Trigo ficou } 50 \text { semanas entre os mais } \\
\text { vendidos nos EUA. }\end{array}$ & $\begin{array}{l}\text { E1 manifesta suspeita, desconfiança, em relação ao } \\
\text { PdV2, dos médicos ("alguns médicos") e, em especial, } \\
\text { do cardiologista William Davis. Primeiro, há o discurso } \\
\text { indireto mediado (segmento 1). Depois, o discurso } \\
\text { direto (segmento 2). E1 não assume o PdV2; não se } \\
\text { posiciona em relação ao seu valor de verdade. }\end{array}$ \\
\hline \multirow{4}{*}{$\begin{array}{l}\text { Excerto } 3 \\
\text { (1) Essa teoria, de que o melhoramento genético do } \\
\text { trigo possa ter criado um monstro, é apenas uma teoria } \\
\text { - e bastante questionada pelos pesquisadores da área. } \\
\text { (2) Isso porque os cruzamentos genéticos ocorrem há } \\
\text { milênios [...]. (3) Não há comprovação científica de que } \\
\text { esse processo tenha modificado a forma como o trigo é } \\
\text { digerido. (4) "Não há um só sistema no organismo que } \\
\text { não seja afetado pelo trigo", ataca Davis. (5) "Da } \\
\text { fadiga à artrite, do desconforto gastrointestinal ao } \\
\text { ganho de peso, todos [esses males] têm como origem o } \\
\text { alimento, de aparência inocente, que cada um de nós } \\
\text { come todas as manhãs", acredita. (6) Por essa tese, o } \\
\text { trigo pode estar nos fazendo mal - e ser o grande } \\
\text { responsável pela epidemia de obesidade no mundo. }\end{array}$} & $\begin{array}{l}\text { Primeiramente, no segmento 1, emprega-se um } \\
\text { discurso indireto, no qual se diz que a tese de William } \\
\text { Davis (PdV2) é uma teoria bastante questionada. L1/E1 } \\
\text { não se responsabiliza pelo PdV2, apesar dos recursos } \\
\text { de atenuação da fiabilidade desse ponto de vista nos } \\
\text { segmentos } 2 \text { e } 3 \text {. }\end{array}$ \\
\hline & $\begin{array}{l}\text { No segmento 4, emprega-se um discurso direto. L1/E1 } \\
\text { não se engaja no PdV2. Atribui a responsabilidade a } \\
\text { E2. }\end{array}$ \\
\hline & $\begin{array}{l}\text { No segmento } 5 \text {, acontece o mesmo que no segmento } 4 \\
\text { (descrito acima). }\end{array}$ \\
\hline & $\begin{array}{l}\text { E1 adota, no segmento 6, o discurso indireto mediado } \\
\text { (mediativo), uma vez que não se engaja em relação ao } \\
\text { conteúdo predicado em tal segmento. L1/E1 comenta, } \\
\text { com suas palavras, a plausibilidade (pode ser verdade) } \\
\text { da tese defendida pelos médicos (PdV2). }\end{array}$ \\
\hline
\end{tabular}

Fonte: elaborado pelos autores.

O fato de L1/E1 se afastar do PdV2 é comprovado por várias marcas linguísticas. Uma dessas marcas é a forma de se referir aos médicos responsabilizados por dizer que o

\footnotetext{
10 Alguns poucos trechos dos enunciados da reportagem (na coluna Excerto) foram retirados, devido aos limites para o presente artigo. Mas buscamos editar de maneira a não comprometer a sistematização.
}

ZANDONAI, Marcos Filipe; GIERING, Maria Eduarda; ALBÉ, Maria Helena. A responsabilidade enunciativa no texto de divulgação científica midiática. Linguagem em (Dis)curso - LemD, Tubarão, SC, v. 18, n. 3, p. 527 543, set./dez. 2018. 
aprimoramento do trigo pode ter gerado malefícios à saúde, no segmento 1 do Excerto 2. Ou seja, é uma questão de nomeação: amenizam-se as certezas sobre o PdV2 por meio do sintagma "alguns médicos". Já que a informação não provém de uma certeza, L1/E1 enuncia apenas plausibilidade do fato, ao dizer que o desenvolvimento do trigo "pode ter ido longe demais". Essa modalização está presente também na afirmação "o trigo pode estar nos fazendo mal" (segmento informacional 6 do Excerto 3).

Já no que concerne à adesão de L1/E1 ao PdV1, o discurso reportado a Eduardo Caeirão serve como apoio para tal PdV no Excerto 1. Já as declarações dos enunciadores citados do PdV2 não assumem apenas essa função, pois os verbos manifestam outros fins por parte de L1/E1, e essas declarações estão direcionadas a outros propósitos, como mostra a análise.

Ainda a respeito da adesão ao PdV1, na citação apresentada no Excerto 1, a oração subordinada adjetiva posposta ao nome do pesquisador Eduardo Caeirão - "explica o pesquisador Eduardo Caeirão, que trabalha com melhoramento genético na Embrapa Trigo" (PANDOLFI, 2014, p. 31) - faz com que a mensagem adquira fiabilidade. Esse "poder epistêmico" deriva da observância à identidade do especialista convocado a falar.

Já ao mediar a fala dos enunciadores que representam o PdV2, L1/E1 também fornece as credenciais, mas salienta traços ligados ao apelo comercial de William Davis, autor cujo livro "ficou 50 semanas entre os mais vendidos nos EUA" (Excerto 2). Para além dessas diferenças de tratamento, é visível essa representação do PdV alheio como algo que confere mais "cientificidade" à reportagem (CORTEZ, 2011; MOIRAND; TOURÉ; RIBEIRO, 2016).

A despeito do esquema de (não) assunção que caracteriza a reportagem examinada, concluímos que a descrença e o rigor de L1/E1 em relação à teoria do PdV2, que é "questionada pelos pesquisadores da área", são devidos ao suposto compromisso com a seriedade, com a cautela, por parte da revista. A restrição de seriedade do contrato (CHARAUDEAU, 2016) faz o locutor transmitir uma imagem de instância competente, comprometida com a credibilidade, o que faz parte da DCM. É da midiatização da ciência. $\mathrm{E}$ as conveniências e interesses sobre certas práticas sociais envolvendo alimentação, incluídas no contrato de comunicação da reportagem, podem estar exercendo pressões sobre a formulação dos pontos de vista.

Ainda se pode explicar cada vez mais e ainda melhor o funcionamento da RE em discursos de DCM, verificando-se o papel dos mecanismos de desresponsabilização/distanciamento na produção de sentidos e na manutenção do status quo dos veículos de comunicação.

\section{REFERÊNCIAS}

ADAM, J.-M. A linguística textual: introdução à análise textual dos discursos. São Paulo: Cortez, 2011.

AUTHIER-REVUZ, J. Palavras incertas: as não-coincidências do dizer. Tradução de Claudia R. Castellanos Pfeiffer, et al. Revisão técnica da tradução Eni Pulccinelli Orlandi. Campinas: Ed. da UNICAMP, 1998. 
BUENO, W. C. As fontes comprometidas do jornalismo científico. In: PORTO, C. de M.; BROTAS, A. M. P.; BORTOLIERO, S. T. Diálogos entre ciência e divulgação científica: leituras contemporâneas. EDUFBA: Salvador, 2011. p. 55-72.

CASTILHO, A. T.; CASTILHO, C. M. M. Advérbios modalizadores. In: ILARI, R. (Org.). Gramática do português falado. Campinas: Editora da UNICAMP, 2002. p. 199-247.

CHARAUDEAU, P. Sobre o discurso científico e sua midiatização. Calidoscópio, v. 14, n. 3, p. 550-556, set./dez. 2016.

CONTE, M. E. Encapsulamento anafórico. In: CAVALCANTE, M.M.; RODRIGUES, B.B.; CIULLA, A. (Org.). Referenciação. São Paulo: Contexto, 2003.

CORTEZ, S. L. Ponto de vista em representação: a construção dos objetos de discurso em reportagens de revista feminina. Investigações, Recife, v. 24, p. 81-101, 2011 (impresso).

GUENTCHÉVA, Z. Manifestations de la catégorie du médiatif dans les temps du français. Langue Française, Paris, v. 102, n. 1, p. 8-23, 1994.

Introduction. In: GUENTCHÉVA, Z. L'énonciation médiatisée. Louvain-Paris: Éditions Peeters, 1996, p. 11-18.

GIERING, M. E. Referenciação e hiperestrutura em textos de divulgação científica para crianças. Linguagem em (Dis)curso, v. 12, n. 3, p. 683-710, set./dez. 2012.

KOCH, I. G. V.; CORTEZ, S. L. A construção heterodialógica dos objetos de discurso por formas nominais referenciais. Revista Virtual de Estudos da Linguagem, v. 13, p. 29-49, 2015.

LOURENÇO, M. das V. N. S.; RODRIGUES, M. das G.S. Considerações sobre o quadro mediativo na petição inicial / Considerations about mediative in initial petition. Revista Linha D'Água, v. 26, p. 71-86, 2013.

MOIRAND, S.; REBOUL-TOURE, S.; RIBEIRO, M. P. A divulgação científica no cruzamento de novas esferas de atividade linguageira. Bakhtiniana, Rev. Estud. Discurso [online]. v. 11, n. 2, p. 137-161, 2016.

NEVES, J. dos S. B. Estudo de estratégias linguísticas de envolvimento e distanciamento no discurso jornalístico. In: SIMPÓSIO NACIONAL e I SIMPÓSIO INTERNACIONAL DE LETRAS E LINGUÍSTICA, 11., 2006, Uberlândia. Múltiplas perspectivas em Linguística-Coletânea de trabalhos apresentados no XI Simpósio Nacional de Letras e Linguística e I Simpósio Internacional de Letras e Linguística, 2006.

NEVES, J. dos S. B.; OLIVEIRA, T. Estratégias linguísticas de distanciamento no discurso jornalístico. Aprender (Portalegre), v. 31, p. 49-55, 2007.

PANDOLFI, R. A verdade sobre o glúten. Fotos: Dulla; design: Fabrício Miranda; edição: Bruno Garattoni; produção: Cíntia Sanchez; colaboração: Andreas Müller, Pedro Henrique Tavares e Tatiana Reckziegel. Superinteressante, São Paulo, n. 335, p. 26-35, jul. 2014.

PASSEGGI, L. et al. A análise textual dos discursos: para uma teoria da produção co(n)textual de sentido. In: BENTES A. C., LEITE, M. Q. (Org.). Linguística de texto e análise da conversação: panorama de pesquisas no Brasil. São Paulo: Cortez, 2010. p. 262-312.

ZANDONAI, M. F.; GIERING, M. E. A glosa em textos de divulgação científica midiática dirigidos ao público infantil. Entrelinhas, v. 7, n. 1, p. 85-104, 2013.

Recebido em: 08/09/17. Aprovado em: 15/06/18.

Title: The enunciative responsibility in text of media scientific popularization Authors: Marcos Filipe Zandonai; Maria Eduarda Giering; Maria Helena Albé

Abstract: This paper aims to reveal marks of (non) assumption of enunciative responsibility in a scientific popularization report published in the magazine Superinteressante. The investigation is based on Textual Analysis of Discourse (TAD), specifically on the notion of enunciative responsibility (ADAM, 2011), as well as on the postulates of Guentchèva (1994, 1996) about the mediative and on the premises of Charaudeau (2016) on science mediatization. This study seeks to understand which representations of the discourse of others are constructed, which make the speaker/enunciator accomplish certain purposes that are specific of the communication context in which he/she is inserted. Three segmented fragments of the report are analyzed, in order to describe the way in which the voices are presented and represented in the text. Even though the text examined does not have an

ZANDONAI, Marcos Filipe; GIERING, Maria Eduarda; ALBÉ, Maria Helena. A responsabilidade enunciativa no texto de divulgação científica midiática. Linguagem em (Dis)curso - LemD, Tubarão, SC, v. 18, n. 3, p. 527 543, set./dez. 2018. 
argumentative purpose and contrasting points of view are presented in the report, the analysis reveals that the speaker expresses different degrees of engagement in relation to another point of view, which indicates his/her positioning about contents attributed to third parties.

Keywords: Scientific popularization in media. Enunciative responsibility. Argumentative orientation.

Titulo: Responsabilidad enunciativa en el texto de divulgación científica mediática

Autores: Marcos Filipe Zandonai; Maria Eduarda Giering; Maria Helena Albé

Resumen: Este artículo tiene el objetivo de mostrar marcas de (no) asunción de responsabilidad enunciativa presentes en un reportaje de divulgación científico mediático publicado en la revista Superinteressante. Para ello, se basa en el Análisis Textual de los Discursos (ATD), específicamente en la noción de responsabilidad enunciativa (RE) (ADAM, 2011), en las teorizaciones de Guentchéva $(1994,1996)$ sobre el mediático, y en las consideraciones de Charaudeau (2016) sobre mediatización de la ciencia. Procura entender que representaciones del discurso ajeno son construidas, las cuales hacen con que el Locutor/Enunciador (L1/E1) cumpla ciertas finalidades, propias del contexto de comunicación en el que está insertado. Analiza tres extractos del reportaje, mediante los cuales describe como son presentadas y representadas las voces del texto. Aunque el reportaje no tenga finalidad propiamente argumentativa y Puntos de Vista (PdV) contrastantes sean expuestos, el análisis evidencia que L1/E1 expresan diferentes grados de encajamiento en relación a uno u otro PdV, lo que indica su posicionamiento sobre los contenidos atribuidos a terceros.

Palabras clave: Divulgación científica. Responsabilidad enunciativa. Orientación argumentativa.

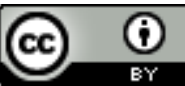

Este texto está licenciado com uma Licença Creative Commons Atribuição 4.0 Internacional.

ZANDONAI, Marcos Filipe; GIERING, Maria Eduarda; ALBÉ, Maria Helena. A responsabilidade enunciativa no texto de divulgação científica midiática. Linguagem em (Dis)curso - LemD, Tubarão, SC, v. 18, n. 3, p. 527 543, set./dez. 2018. 